Egyptian Journal of Botany

\title{
Antifungal Potential of the Bioactive Constituents in Extracts of the Mostly Untapped Brown Seaweed Hormophysa cuneiformis from The Egyptian Coastal Waters
}

\author{
Samar S. Mohamed ${ }^{(1) \#}$, Abdullah A. Saber ${ }^{(2)}$ \\ ${ }^{(1)}$ Microbiology Department, Faculty of Science, AinShams University, Cairo, Egypt; \\ ${ }^{(2)}$ Botany Department, Faculty of Science, Ain Shams University, Cairo, Egypt.
}

\begin{abstract}
M YCOSES and plant fungal pathogens are limiting factors highly affecting public health and crop production. Some fungal strains have been documented to be resistant to the commonly used drugs. Therefore, finding out new and pivotal antifungal drugs is becoming a global priority. Herein, we evaluated the in vitro antifungal activities of different crude polar (methanol and ethyl acetate) and non-polar (chloroform and petroleum ether) extracts of the mostly untapped brown seaweed Hormophysa cuneiformis (order Fucales, Phaeophyceae), in the Egyptian coastal waters, against eight pathogenic fungi: Aspergillus flavus, A. fumigatus, Candida albicans and Trichosporonas ahii (as human pathogens), and Alternaria alternata, Cladosporium herbarum, Fusarium oxysporum and Penicillium digitatum (as plant pathogens). The agar well diffusion assay was applied. Our findings showed that the chloroform extract only exhibited a potential antifungal activity against all tested fungal isolates, particularly $T$. asahii, C. albicans, A. fumigatus and C. herbarum, while the other extracts had relatively no remarkable effects. The minimum inhibitory concentrations (MICs) ranged between 0.78 and $6.25 \mu \mathrm{g} \cdot \mathrm{ml}^{-1}$ and these values are very close to those of the standard antifungal drug amphotericin B $\left(0.63-5 \mu \mathrm{g} \cdot \mathrm{ml}^{-1}\right)$. GC-MS analysis of the crude chloroform extract revealed 45 different bioactive compounds, mainly including 18 different species of saturated, monounsaturated and polyunsaturated fatty acids $(71.48 \%)$ and some essential oils. The major constituents were arachidonic $(\mathrm{C} 20: 4, \omega-6 ; 16.18 \%)$, oleic $(\mathrm{C} 18: 1, \omega-9 ; 15.61 \%)$, palmitic $(\mathrm{C} 16: 0 ; 9.18 \%)$ and dihomo- $\gamma$-linolenic $(\mathrm{C} 20: 3, \omega-6 ; 8.97 \%)$ fatty acids.
\end{abstract}

Keywords: Hormophysa cuneiformis, Brown seaweeds, Fatty acids, Essential oils, Antifungal activity, Pathogenic fungi.

\section{Introduction}

Fungi are an important component of most ecosystems on Earth; however some of them are considered main pathogenic invaders in immunocompromised persons, causing diverse kinds of mycoses with an increasing threat to human health (Abd Elmegeed et al., 2015; Ouf et al., 2016). It is well known that infections caused by different human fungal pathogens such as Candida spp. and/or Aspergillus spp. can result in some serious diseases and even death (Brown et al., 2012). Moreover, Candida albicans, a common colonizer of the mucosal surface of the gut, has been classified among the highest five infectious agent causing sepsis (Vincent et al., 2009). Currently, invasive candidiasis is the most common fungal disease among hospitalized patients and it has been reported that it is responsible for mortality rates up to $40 \%$ even when patients are received an antifungal therapy (Garcia-Solache \& Casadevall, 2010; Kullberg \& Arendrup, 2015). Likewise, the mold Aspergillus fumigatus is the most frequent cause of invasive fungal infection in immunosuppressed individuals, including patients receiving immunosuppressive

\#Corresponding author email: samar_samer78@yahoo.com $\quad$ Tel: (+20) 1144858820.

Received 8/10/2018; Accepted 2/5/2019

DOI: $10.21608 /$ ejbo.2019.5516.1225

Edited by: Prof. Mostafa M..Elsheekh, Faculty of Science, Tanta University, Tanta, Egypt.

C2019 National Information and Documentation Center (NIDOC) 
therapy for neoplastic or autoimmune diseases, organ transplant recipients, and AIDS patients. Also, it has been found that $A$. fumigatus primarily causes invasive infection in the lung and represents a major cause of morbidity and mortality ranging from $40 \sim 90 \%$ in high-risk populations (Dagenais \& Keller, 2009).

On the other hand, plant diseases caused by fungal pathogens have been addressed as a worldwide economic threat to the agricultural sustainable development (Fisher et al., 2012 and Hamed et al., 2018). Furthermore, postharvest fungal pathogens limit shelf-life of fresh commodities, contributing to a deterioration of quality, reduction of nutrients and market value, and high possibility of mycotox in contamination (El-Hossary et al., 2017). Control and management of plant fungal infections is very important to produce healthy food crops and consequently this strategy will has significant positive impacts on agricultural use of lands, waters, fuels and other inputs (Dean et al., 2012; Martinelli et al., 2015).

Since fungi are metabolically similar to mammalian cells, few pathogen-specific targets are available, making antifungal research more challenging (El-Hossary et al., 2017). Given the harmful side effects of the synthetic fungicides on the environment and crops as well as the resistance developed to some of them, there is nowadays an urgent need to find out new and ecofriendly alternatives effective on different fungal classes (Righini et al., 2018).

In general, the marine environments are characterized by structurally diverse and biologically active secondary metabolites and some of them have inspired the development of new bioactive compounds of therapeutic potential. Seaweeds (or marine macroalgae) in general produce a variety of bioactive compounds with a wide range of antimicrobial activity (Zerrifi et al., 2018). Among these secondary metabolites, several pivotal compounds with noteworthy antifungal activities have been addressed and isolated from the seaweeds (Liu et al., 2013; El-Hossary et al., 2017). For example, the natural antifungal Lobophorolide, a 22-membered cyclic lactone, had been isolated from the marine brown alga Lobophora variegata, growing in the Red Sea, Hurghada (Egypt) and the islands of the Bahamas. Lobophorolide exhibited a potent antifungal activity against the saprophytic deuteromycete Dendryphiella salina and the pathogenic ascomycete Lindra thalassiae. Also, this natural compound has an antifungal potential against the amphotericin-resistant-strain $C$. albicans (El-Hossary et al., 2017).

In Egypt, seaweeds are widely distributed along coasts of the Mediterranean (e.g., Shabaka, 2018) and Red Seas (e.g., El-Sharouny et al. 2001). They are rich resources of bioactive compounds with high possibility for use in promising development of recent pharmaceutical agents (Abdel-Raouf et al., 2008; Ibraheem et al., 2017). Previous studies on antimicrobial (mainly antibacterial with little antifungal) characterizations of the Egyptian seaweeds have been primarily focused on the most cosmopolitan and well identified species, e.g. Cystoseira compressa, C. myrica, Dictyota dichotoma, Hydroclathrus clathratus, Padina pavonica, Sargassum hornschuchii, S. latifolium, S. ramifolium, S. vulgare and Turbinaria ornata as members of brown macroalgae, Acanthophora spicifera, Corallina officinalis, Galaxaura elongata, Jania rubens, Liagora farinosa, Pterocladia capillacea, and Sarcodiotheca furcata species of Rhodophyta, and Caulerpa racemosa, Codium tomentosum, Ulva fasciata and U. lactuca belonging to Chlorophyta (e.g., Ibraheem et al., 2012; El-Sheekh et al., 2014; Fathy et al., 2017; Ibraheem et al., 2017).

The brown seaweed Hormophysa cuneiformis (J. F. Gmelin) P. C. Silva (Fucales, Phaeophyta) is one of the algal flora inhabiting the Egyptian Red Sea coast, mainly at Hurghada and Safaga cities (ElSharouny, 2001). To the best of our knowledge and the available literature, there have been no studies regarding the phytochemical and antimicrobial properties of this seaweed in the Egyptian water habitats. However, some little information about phytochemical constituents, antibacterial and antihyperlipidemic activities of this species [and its synonym $H$. triquetra (C.Agardh) Kützing] had been discussed worldwide in some previous studies (e.g., Heiba et al., 1997; El Shoubaky \& Salem, 2014a, b; Abdel-Raouf et al., 2015).

The aim of this work was to evaluate for the first time the in vitro antifungal activities of the different extracts (methanol, ethyl acetate, chloroform and petroleum ether) from the brown seaweed $H$. cuneiformis, not well studied in the Egyptian coastal waters, against eight human and plant fungal pathogens. Analysis of the crude seaweed chloroform extract, as the most potent one, for 
detecting the bioactive substances particularly fatty acids profiling was also carried out using a gas chromatography-mass spectrometry (GC-MS) approach.

\section{Materials and Methods}

\section{Algal sampling and identification}

Specimens of the brown seaweed Hormophysa cuneiformis (Figs. 1 A-B) were collected on October $26^{\text {th }} 2017$ from the littoral zone of rocky shorelines in Hurghada city $\left(27^{\circ} 15^{\prime} 58.45^{\prime \prime} \mathrm{N}\right.$, $\left.33^{\circ} 48^{\prime} 57.09^{\prime \prime} \mathrm{E}\right)$, the Red Sea coast of Egypt. In the field, thalli were washed well to remove any epiphytes and sand particles, kept in sterile clean plastic bottles and then transported chilled in the ice-box to the laboratory. The algal specimens were washed well again in the lab using tap water to be completely free from any debris, salts and sand particles, and then shade-air dried at the room temperature. The samples were pulverized to a fine powder using an electric blender and then stored well in sterile clean plastic bags in the refrigerator until further studies. Thalli of $H$. cuneiformis were morphologically identified following the relevant literature adopted by Jha et al. (2009) and Dixon \& Huisman (2015). Voucher specimens of the brown seaweed $H$. cuneiformis including fixed materials $(2 \% \mathrm{v} / \mathrm{v}$ formaldehyde final conc.) and herbarium sheets were deposited at the Phycology Unit (No. 341), the Botany Department, Faculty of Science at Ain Shams University (Cairo, Egypt).

\section{Preparation of the seaweed extracts}

The extraction process was performed separately using four different organic solvents in the order of increased polarity: Petroleum ether, chloroform, ethyl acetate and methanol.100gm of the finely powdered seaweed were added to $400 \mathrm{ml}$ of each solvent $(1: 4 \mathrm{w} / \mathrm{v})$ following the protocol adopted by Fathy et al. (2017) and the extraction process was then carried out by incubation in an orbital shaker (Unimax 2010, Heidolph Instruments, Schwabach, Germany) at $175 \mathrm{rpm}$. The crude seaweed extracts were filtered after $6 \mathrm{hr}$ incubation through Whatman No.1 filter paper (Whatman International, Ltd., Maidstone, England) and then the seaweed material was re-suspended again in each solvent (1: $4 \mathrm{w} / \mathrm{v})$ and filtered after $24 \mathrm{hr}$ to ensure exhaustive extraction occurred. The crude seaweed extracts were combined and the solvents were evaporated by a rotary evaporator (Büchi R-200, Marshall Scientific, Minnesota, USA) at $40^{\circ} \mathrm{C}$. The crude seaweed extracts were fast-frozen in liquid nitrogen and stored at $-20^{\circ} \mathrm{C}$ until further use and re-dissolved in the respective solvent on application.

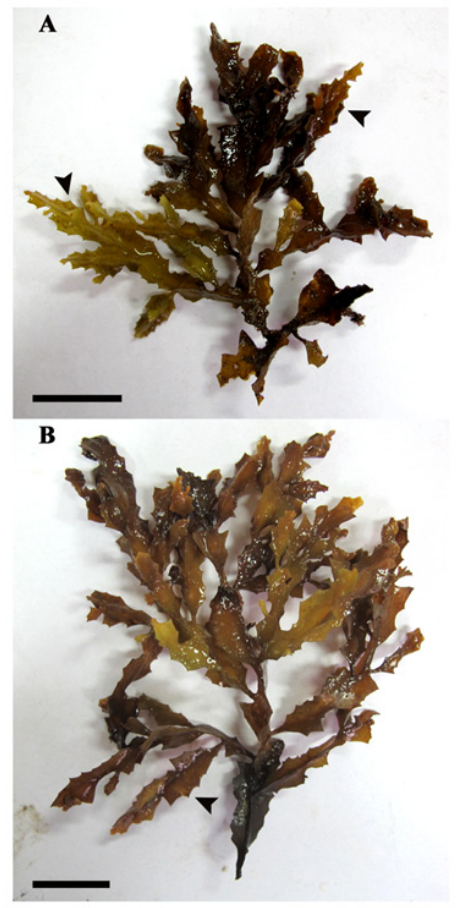

Figs. 1 (A-B). Morphological characteristics of the brown seaweed Hormophysa cuneiformis showing thallus habit and pseudo-dichotomously, articulated branches with dentate margins (arrowheads) [Scale bar $=5 \mathrm{~cm}]$.

Fungal isolates used in this study

Eight human and plant pathogenic fungal species, including Aspergillus fumigatus, $A$. flavus, Candida albicans, Trichosporona sahii, Alternaria alternata, Cladosporium herbarum, Fusarium oxysporum and Penicillium digitatum, were used as tested organisms in this study. Yeast species were cultured on sabouraud dextrose agar at $30^{\circ} \mathrm{C}$ for $24 \mathrm{hr}$, while filamentous fungi were grown on potato dextrose agar at $28^{\circ} \mathrm{C}$ for $4-7$ days. The fungal isolates used in this study were kept at the Microbiology Department, Faculty of Science, Ain Shams University (Cairo, Egypt).

\section{Inoculum preparation}

Yeast inoculum suspensions were prepared following the NCCLS M27-A2 method (NCCLS, 2002a). The turbidity was spectrophotometrically measured at a wavelength of $530 \mathrm{~nm}$ and then was adjusted to match a $0.5 \mathrm{McF}$ arland density standard, resulting in a concentration of $1-5 \times 10^{6}$ 
yeast cells.ml ${ }^{-1}$. For filamentous fungal species, inoculum suspensions were prepared from fresh mature 3 to 5 days old cultures grown on potato dextrose agar slants. The colonies were covered with $5 \mathrm{ml}$ of sterile distilled water. Tween 20 (5\%) was added to facilitate the preparation of fungal inocula. The suspensions were obtained by exhaustive scraping of the surface with a sterile loop. The inoculum size was determined spectrophotometrically at a wavelength of $530 \mathrm{~nm}$ until reaching a transmittance level of $80-82 \%$ according to M38-Aguidelines (NCCLS, 2002b).

\section{Screening antifungal activities of $H$. cuneiformis extracts}

Antifungal activities of the different crude seaweed extracts were performed using the agar well-diffusion assay (Magaldi et al., 2004). Yeast and fungal suspensions were streaked evenly on Mueller-Hinton agar plates $(9 \mathrm{~cm}$ in diameter) using sterile clean cotton swabs. After that, $6 \mathrm{~mm}$ holes were aseptically punched using a sterile cork borer. $200 \mu \mathrm{l}$ of the standard antifungal medication "amphotericin B" $\left(0.1 \mathrm{mg} \cdot \mathrm{ml}^{-1}, \mathrm{w} / \mathrm{v}\right)$, as a positive control and the crude organic algal extracts $(1 \mathrm{mg}$. $\mathrm{ml}^{-1}, \mathrm{w} / \mathrm{v}$ ) were injected inside these wells. The inoculated plates were incubated at $30^{\circ} \mathrm{C}$ for $24 \mathrm{hr}$ for yeast species and 2-4 days for the filamentous fungal species. The assay was carried out in triplicates and the plates were carefully examined to detect presence or absence of the fungal growths, as well as to measure diameters of the inhibition zones. The results were expressed as mean values \pm standard deviation.

\section{Broth microdilution assay}

The minimum inhibitory concentration (MIC) for the crude algal-chloroform extract was determined, as the only potent antifungal extract in this study, using broth microdilution assay according to CLSI document M38-A2 (2002). MIC was performed in RPMI 1640 medium (Sigma-Aldrich, Mississauga, Ontario, Canada) with L-glutamine but without sodium bicarbonate and buffered with $0.165 \mathrm{M}$ morpholinepropanesulfonic acid (MOPS) (Sigma-Aldrich) at pH 7.0. A sterile microdilution plate (96-flat bottomed wells) was used for each strain so that $100 \mu 1$ of RPMI media were added to each well then another $100 \mu \mathrm{l}$ of the solution of standard antifungal drugor the crude chloroform extract of Hormophysa cuneiformis were added to a well in the $1^{\text {st }}$ column. Two-fold serial dilutions were made using the multichannel pipette so that rows 1-10 will contain the series of dilutions of the $100 \mu 1$ seaweed chloroform extracts. $100 \mu 1$ of inoculum suspension were added to each well. The $11^{\text {th }}$ row which served as the positive growth control contained $100 \mu 1$ of inoculum suspension and $100 \mu 1$ of free medium whereas the $12^{\text {th }}$ row which served as negative control only contained $200 \mu 1$ of RPMI broth. Microdilution trays were incubated at $30^{\circ} \mathrm{C}$. The MICs were read after 4-7 days. MIC was determined as the point at which there was $100 \%$ inhibition of the fungal growth as compared to the control when read visually in the microtitre plates (Hammer et al., 2003; da Silva Barros et al., 2007).

\section{Lipids extraction and transmethylation}

Total lipids were extracted from the seaweed specimens following the method of Folch et al. (1957). Briefly, the crude seaweed extract was resuspended in $10 \mathrm{ml}$ of chloroform/methanol 2:1 $(\mathrm{v} / \mathrm{v})$, sonicated for $15 \mathrm{~min}$ in an ultrasonic bath (Sonorex Super, Bandelin electronics, Berlin, Germany), and centrifuged at 3000x $g$ for $10 \mathrm{~min}$ at room temperature to separate the organic phase (bottom layer). The procedure was repeated two times and the organic phases were collected, washed with $20 \mathrm{ml}$ of a $5 \% \mathrm{NaCl}$ solution, filtered using glass filters and finally reduced to dryness on a rotary evaporator (BüchiLabortechnik AG, Flawil, Switzerland). Fatty acids methyl esters were prepared following a modified version of the procedure described by Mason \& Waller (1964). $250 \mu 1$ methanolic $\mathrm{HCl}(3 \mathrm{M})$ were added into $1 \mathrm{ml}$ of each lipidomic extract. The tubes were then capped tightly with a Teflon-lined cap and subsequently incubated at $60^{\circ} \mathrm{C}$ for $20 \mathrm{~min}$.

Gas chromatography-mass spectrometry (GC/MS) analysis

Fatty acid methyl esters and other phytochemical compounds, were analyzed by GC-MS using a HP-5MS capillary column $(30 \mathrm{~m} \times$ $0.25 \mathrm{~mm}$ ID, $0.25 \mu \mathrm{m}$ film thickness) in a $7890 \mathrm{~B}$ gas chromatograph system (Agilent Technologies Co., Santa Clara, USA) coupled to a 5977A mass selective detector. The carrier gas was helium with a constant flow rate of $1.8 \mathrm{ml} \cdot \mathrm{min}^{-1}$. The oven temperature was initially kept at $40^{\circ} \mathrm{C}$ for $3 \mathrm{~min}$ and then ramped at $25^{\circ} \mathrm{C} \cdot \mathrm{min}^{-1}$ to $300^{\circ} \mathrm{C}$ for $3 \mathrm{~min} .1 .0 \mu \mathrm{l}$ of each sample solution was injected. Mass spectra were obtained by electron ionization (EI) at $70 \mathrm{eV}$. The compounds were identified by comparison of their mass spectra with those of the NIST/EPA/ NIH mass spectral databases. 


\section{Statistical analysis}

All experiments were carried out in triplicates and the results were presented as the mean \pm standard deviation (SD).

\section{$\underline{\text { Results }}$}

In vitro susceptibility screening of the antifungal activities of H. cuneiformis extracts

Testing of the different antifungal crude extracts of the brown seaweed $H$. cuneiformis used in this study showed that only the crude chloroform extract exhibited an antifungal activity against all tested fungal isolates while the other extracts had relatively no remarkable effects. Notably, T. asahii, C. albicans, A. fumigatus and C. herbarum were the most susceptible fungal isolates to the crude chloroform extract, as compared to other treatments with the standard antifungal drug amphotericin B, with average inhibition zone values of $21.67 \pm 0.58$, $21.33 \pm 0.58, \quad 18.67 \pm 0.58$ and $17.67 \pm 0.58 \mathrm{~mm}$, respectively (Table 1 and Figs. $2 \mathrm{~A}-\mathrm{H}$ ).

TABLE 1. In vitro antifungal activities of the crude chloroform extract of the brown seaweed Hormophysa cuneiformis against fungal isolates used in this study using well diffusion assay.

\begin{tabular}{lcc}
\hline Fungal isolates & \multicolumn{2}{c}{$\begin{array}{c}\text { Average diameters of } \\
\text { inhibition zones (mm) }\end{array}$} \\
\cline { 2 - 3 } & $\begin{array}{c}\text { crude } \\
\text { chloroform } \\
\text { extract of } \boldsymbol{H} \text {. } \\
\text { cuneiformis }\end{array}$ & $\begin{array}{c}\text { Amphotericin } \\
\text { B (+ve } \\
\text { control) }\end{array}$ \\
\hline Alternaria alternata & $12.0 \pm 1.0$ & $20.33 \pm 1.15$ \\
$\begin{array}{l}\text { Aspergillus } \\
\text { fumigatus }\end{array}$ & $18.67 \pm 0.58$ & $23.0 \pm 1.0$ \\
Aspergillus flavus & $15.67 \pm 0.58$ & $20.67 \pm 0.58$ \\
Candida albicans & $21.33 \pm 0.58$ & $24.67 \pm 0.58$ \\
$\begin{array}{l}\text { Cladosporium } \\
\text { herbarum }\end{array}$ & $17.67 \pm 0.58$ & $20.33 \pm 0.58$ \\
$\begin{array}{l}\text { Fusarium } \\
\text { oxysporum }\end{array}$ & $13.67 \pm 0.58$ & $18.33 \pm 0.58$ \\
$\begin{array}{l}\text { Penicillum } \\
\text { digitatum }\end{array}$ & $13.33 \pm 0.58$ & $14.0 \pm 1.0$ \\
$\begin{array}{l}\text { Trichosporon asahii } \\
\text { Data }\end{array}$ & $21.67 \pm 0.58$ & $24.0 \pm 1.0$ \\
\hline
\end{tabular}

Data are expressed as mean \pm SD.

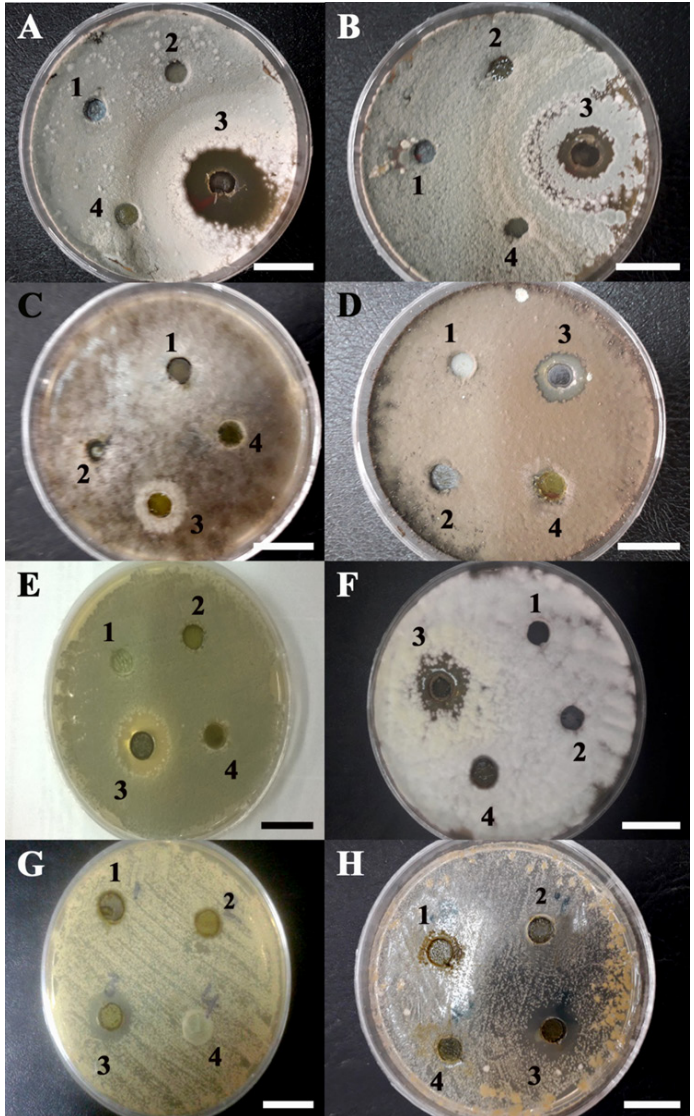

Figs. 2 (A-H). In vitro susceptibility of fungal isolates investigated in this study to the different crude extracts of brown seaweed Hormophysa cuneiformis using the well diffusion assay. 1: Methanol extract, 2: Ethyl acetate extract, 3: Chloroform extract, 4: Petroleum ether extract. A: Aspergillus flavus, B: Penicillium digitatum, C: Alternaria alternata, D: Cladosporium herbarum, E: Aspergillus fumigatus, F: Fusarium oxysporum, G: Candida albicans, $\mathrm{H}$ : Trichosporon asahii [Scale bar $=2 \mathrm{~cm}]$.

Determination of the MIC values using broth microdilution assay

The minimum inhibitory concentrations (MICs) of the crude chloroform extract of H.cuneiformis specimens are shown in Table 2. The obtained results confirm that there is significant and potent antifungal activity for this algal extract against all tested fungal isolates at low concentrations. MICs ranged between 0.78 and $6.25 \mu \mathrm{g} \cdot \mathrm{ml}^{-1}$. These inhibitory concentrations are considered significant and very close to those of the standard antifungal drug amphotericin B $\left(0.63-5 \mu \mathrm{g} \cdot \mathrm{ml}^{-1}\right)$, especially against $C$. albicans, T. asahii, A. fumigatus and C. herbarum. 
TABLE 2. Minimum inhibitory concentrations (MICs) of the crude chloroform extract of the brown seaweed Hormophysa cuneiformis against fungal isolates investigated in this study.

\begin{tabular}{|c|c|c|}
\hline \multirow[b]{2}{*}{ Fungal isolates } & \multicolumn{2}{|c|}{$\begin{array}{l}\text { Minimum inhibitory } \\
\text { concentrations }\left(\mu \mathrm{g} \cdot \mathrm{ml}^{-1}\right)\end{array}$} \\
\hline & $\begin{array}{c}\text { Crude chloroform } \\
\text { extract of } H \text {. } \\
\text { cuneiformis }\end{array}$ & $\begin{array}{c}\text { Amphotericin } \\
\text { B } \\
\text { (+ve control) }\end{array}$ \\
\hline $\begin{array}{l}\text { Alternaria } \\
\text { alternata }\end{array}$ & 6.25 & 5.0 \\
\hline $\begin{array}{l}\text { Aspergillus } \\
\text { fumigatus }\end{array}$ & 0.78 & 0.63 \\
\hline $\begin{array}{l}\text { Aspergillus } \\
\text { flavus }\end{array}$ & 6.25 & 5.0 \\
\hline $\begin{array}{l}\text { Candida } \\
\text { albicans }\end{array}$ & 0.78 & 0.63 \\
\hline $\begin{array}{l}\text { Cladosporium } \\
\text { herbarum }\end{array}$ & 1.56 & 1.25 \\
\hline $\begin{array}{l}\text { Fusarium } \\
\text { oxysporum }\end{array}$ & 6.25 & 5.0 \\
\hline $\begin{array}{l}\text { Penicillum } \\
\text { digitatum }\end{array}$ & 6.25 & 5.0 \\
\hline $\begin{array}{l}\text { Trichosporon } \\
\text { asahii }\end{array}$ & 1.56 & 0.63 \\
\hline
\end{tabular}

Phytochemical constituent analysis of the brown seaweed chloroform extract

GC-MS analysis of the chloroform extract of the brown seaweed $H$. cuneiformis investigated in this study revealed that this extract contained 45 different bioactive compounds, which mainly represented saturated and unsaturated fatty acids (18 different species) and some essential oils (25 different compounds), with minor concentrations of the terpene compound phytol and the steroid constituent stigmastan-6,22-dien, 3,5-dedihydro(Table 3 and Fig. 3). Fatty acids had the highest relative concentrations (peak areas) with respect to other phytochemical constituents $(71.48 \%)$. They ranged from C12:0 to C24:0. Saturated fatty acids (SFAs) were represented by nine different species with a total peak area of approximately 18\%. Palmitic (C16:0), myristic (C14:0) and stearic (C18:0) fatty acids were the predominant species with relative concentration values of $9.18,2.69$, and $2.38 \%$, respectively. As far the monounsaturated fatty acids (MUFAs), oleic $(\mathrm{C} 18: 1, \omega-9)$ and palmitoleic $(\mathrm{C} 16: 1, \omega-7)$ acids had the relative concentrations of 15.61 and $3.3 \%$, respectively. Polyunsaturated fatty acids (PUFAs) constituted the major bulk of the fatty acids with a total peak area of ca. $35 \%$, where arachidonic (C20:4, $\omega-6)$, dihomo- $\gamma$-linolenic $(\mathrm{C} 20: 3, \omega-6)$ and cis-11,14-eicosadienoic (C20:2, $\omega-6)$ fatty acids were the most prevailing species. Regarding to the essential oils, although they were represented by a wide array of different compounds, but most of them were onlypresent in lower concentrations as compared to those of fatty acids (check Table 3 for more details).

\section{Discussion}

Seaweeds in general have biologically active compounds which are very effective in inhibiting the growth of many pathogenic microorganisms including fungi (e.g., Shobier et al., 2016; Ibraheem et al., 2017; Zerrifi et al., 2018). In this study, the antifungal activity of the brown seaweed $H$. cuneiformis was evaluated against eight pathogenic human and plant fungal isolates. The crude seaweed chloroform extract had significant antifungal activities against all tested fungal pathogens, particularly against $C$. herbarum, A. fumigatus, C. albicans and T. asahii, and inhibited their growths at low MIC values ranged between 0.78 and $6.25 \mu \mathrm{g} \cdot \mathrm{ml}^{-1}$. These inhibitory concentrations are very close to those of the standard antifungal drug amphotericin B $\left(0.63-5 \mu \mathrm{g} \cdot \mathrm{ml}^{-1}\right)$. Other algal extracts had no noticeable antifungal effects. This is consistent with Guedes et al. (2012) who showed that apolar extracts, like chloroform, have the best activity against important pathogenic dermatophytes and Candida species. Similarly, Mhadhebi et al. (2012) stated that chloroform extracts of the brown seaweeds Cystoseira crinita and $C$. sedoides have the maximum antifungal activity against C. albicans. Also, a recent report by Soliman et al. (2018) confirmed that chloroform extract of the red seaweed Gracilaria confervoides has the maximum antifungal activity against the plantinfecting fungus Rhizoctoni asolani. In addition, the published review of Zerrifi et al. (2018) on the seaweed bioactive compounds against pathogens, including fungi, reported that the antimicrobial activity mainly depends upon the type of extraction solvent used as well as the algal species. In this context, our findings support the hypothesis assuming that different solvent extracts from the same seaweed are characterized by different antimicrobial activities based on the polarity of the solvent used and the chemical structures of the bioactive substances extracted (Guedes et al., 2012). 
TABLE 3. GC-MS analysis of the crude chloroform extract of Hormophysa cuneiformis specimens investigated in this study*.

Compounds identified

RT (min)

Megastigma-4,6(Z),8(Z)-triene

2-Furanacetic acid, .alpha.-hydroxy-

1-Butene, 1,1,3,3,4,4-hexachloro-

1-Tetradecene

Tetradecane

Pentadecane

Lauric acid (C12:0)

Phenol, 3,5-bis(1,1-dimethylethyl)-

Benzene, 1,3,5-trimethoxy-

Cetene

Hexadecane

Bicyclo[3.1.1]heptan-2-one, 6,6-dimethyl-, (1R)-

2(1H)-Naphthalenone, octahydro-4a, 7,7-trimethyl-, trans-

Oxirane, tetradecyl-

Pentadecafluorooctanoic acid, octadecyl ester

17-Pentatriacontene

Myristic acid (C14:0)

E-15-Heptadecenal

Octadecane

Pentadecanoic acid (C15:0)

Phytol

Cyclohexene, 4-(4-ethylcyclohexyl)-1-pentyl-

Palmitoleic acid (C16:1, $\omega-7)$

Palmitic acid (C16:0)

Benzenepropanoic acid, 3,5-bis(1,1-dimethylethyl)-4-hydroxy-

1-Nonadecene

Margaric acid (C17:0)

Linoleic acid (C18:2, $\omega-6)$

1,4,8-Dodecatriene, (E,E,E)-

Oleic acid (C18:1, $\omega-9)$

Cycloheptanecarboxylic acid ( $\omega-$ fatty acid)

Stearic acid (C18:0)

Rumenic acid (C18:2, $\omega-7)$

\begin{tabular}{|c|c|}
\hline 7.4343 & 0.1408 \\
\hline 8.3504 & 0.0615 \\
\hline 8.5092 & 0.1485 \\
\hline 8.7104 & 0.2294 \\
\hline 8.7475 & 0.1482 \\
\hline 9.2718 & 0.0833 \\
\hline 9.4094 & 0.1903 \\
\hline 9.4412 & 0.1537 \\
\hline 9.6265 & 0.4278 \\
\hline 9.7324 & 0.8784 \\
\hline 9.7642 & 0.4404 \\
\hline 10.1137 & 0.9054 \\
\hline 10.1931 & 0.3784 \\
\hline 10.2249 & 0.3894 \\
\hline 10.2514 & 0.2385 \\
\hline 10.2726 & 0.3321 \\
\hline 10.3626 & 2.6879 \\
\hline 10.6485 & 1.4427 \\
\hline 10.6697 & 0.6034 \\
\hline 10.7915 & 1.1555 \\
\hline 11.0298 & 0.7468 \\
\hline 11.0880 & 0.5448 \\
\hline 11.1463 & 3.3021 \\
\hline 11.2416 & 9.1774 \\
\hline 11.3528 & 0.6230 \\
\hline 11.4746 & 1.7750 \\
\hline 11.5329 & 0.6217 \\
\hline 11.6070 & 0.3946 \\
\hline 11.6811 & 0.4622 \\
\hline 11.9512 & 15.6097 \\
\hline 11.9671 & 3.6337 \\
\hline 12.0094 & 2.3761 \\
\hline 12.0783 & 0.7053 \\
\hline
\end{tabular}


TABLE 3. Cont.

\begin{tabular}{|c|c|c|}
\hline Compounds identified & RT (min) & Peak area $(\%)$ \\
\hline 2-Furanoctanoic acid, 5-hexyl- (C18:2, $\omega-6)$ & 12.1259 & 1.0542 \\
\hline 1-Docosene & 12.2318 & 2.3682 \\
\hline Arachidonic acid (C20:4, $\omega-6)$ & 12.5601 & 16.1753 \\
\hline Dihomo- $\gamma$-linolenic acid (C20:3, $\omega-6)$ & 12.6078 & 8.9651 \\
\hline cis-11,14-Eicosadienoic acid $(\mathrm{C} 20: 2, \omega-6)$ & 12.6449 & 3.7476 \\
\hline Arachidic acid (C20:0) & 12.7084 & 1.1622 \\
\hline Sclareoloxide(Cis-A/B) & 13.1426 & 0.4139 \\
\hline Docosanoic acid (C22:0) & 13.3597 & 0.4455 \\
\hline Di-n-octyl phthalate & 13.4815 & 3.5535 \\
\hline 9-Hexacosene & 13.5557 & 0.6253 \\
\hline Lignoceric acid (C24:0) & 14.0269 & 0.0804 \\
\hline Stigmastan-6,22-dien, 3,5-dedihydro- & 15.9915 & 0.6675 \\
\hline$\sum$ saturated fatty acids (SFAs) & \multicolumn{2}{|c|}{$17.9 \%$ of the total fatty acids } \\
\hline$\sum$ monounsaturated fatty acids (MUFAs) & \multicolumn{2}{|c|}{$18.91 \%$ of the total fatty acids } \\
\hline$\sum$ polyunsaturated fatty acids (PUFAs) & \multicolumn{2}{|c|}{$34.68 \%$ of the total fatty acids } \\
\hline
\end{tabular}

${ }^{*}$ Peak area (or percentage composition) of compounds identified are relative to other constituents within the same extract. Fatty acids are indicated in bold.

Specimens of the brown seaweed $H$. cuneiformis investigated in this study had high amounts of fatty acids with variable degrees of saturation indices: SFAs (17.9\%), MUFAs (18.91\%), and PUFAs (34.68\%). These results are is in good agreement with that reported by Heiba et al. (1997) during their study on the brown macroalga $H$. triquetra (currently regarded as a synonym of $H$. cuneiformis) collected from the Qatari coasts. They reported 25 different fatty acid species; most of them belonged to the PUFAs (40.9\%). The antifungal activity of the $H$. cuneiformis specimens investigated in this study seems likely ascribed to the synergistic effect exerted by saturated (mainly palmitic, myristic and stearic), monounsaturated $\omega-9$ oleic, and polyunsaturated (particularly arachidonic, dihomo- $\gamma$-linolenic and cis-11,14-eicosadienoic) fatty acids, in addition to some essential oils. In accordance with these observations, El Shoubaky \& Salem (2014 a) investigated the antibacterial activity of the crude acetone extract of H. triquetra collected from the Red Sea coast in Saudi Arabia and found that this brown seaweed has a remarkable antibacterial activity against the tested bacterial strains due to its high content of fatty acids (65.36\%), mainly myristic, palmitic, margaric, oleic, stearic, nonadecanoic, and cis-10nonadecenoic acids. Also, Ells et al. (2009) found that the polyunsaturated $\omega-6$ arachidonic acid (C20:4) has the potential to increase antifungal susceptibility of biofilms formed by two closely related Candida species, leading to reduction of the dose of the antimycotic agent required to inhibit biofilm formation. Similarly, in other studies, biofilm formation/development of pathogenic fungi Candida albicans and C. dubliniensis have been found to be inhibited by monounsaturated/ polyunsaturated antimicrobial fatty acids, e.g. stearidonic $(18: 4, n-3)$, eicosapentaenoic (20:5, n-3), docosapentaenoic (22:5, n-3), and docosahexaenoic $(22: 6, n-3)$ fatty acids and their brominated/acetylene derivatives extracted and purified from different marine algae (Thibane et al., 2010, 2012). In addition, a review by Pohl et al. (2011) on free fatty acids outlined that the most effective saturated and unsaturated species characterized by antifungal activity. Some of these fatty acids were identified in the chloroform extract analyzed in this study, e.g. lauric (C12:0), myristic (C14:0), palmitic (C16:0), monounsaturated $\omega-7$ palmitoleic (C16:1), monounsaturated $\omega-9$ oleic $(\mathrm{C} 18: 1)$ and polyunsaturated $\omega-6$ linoleic $(\mathrm{C} 18: 2)$ fatty acids. 


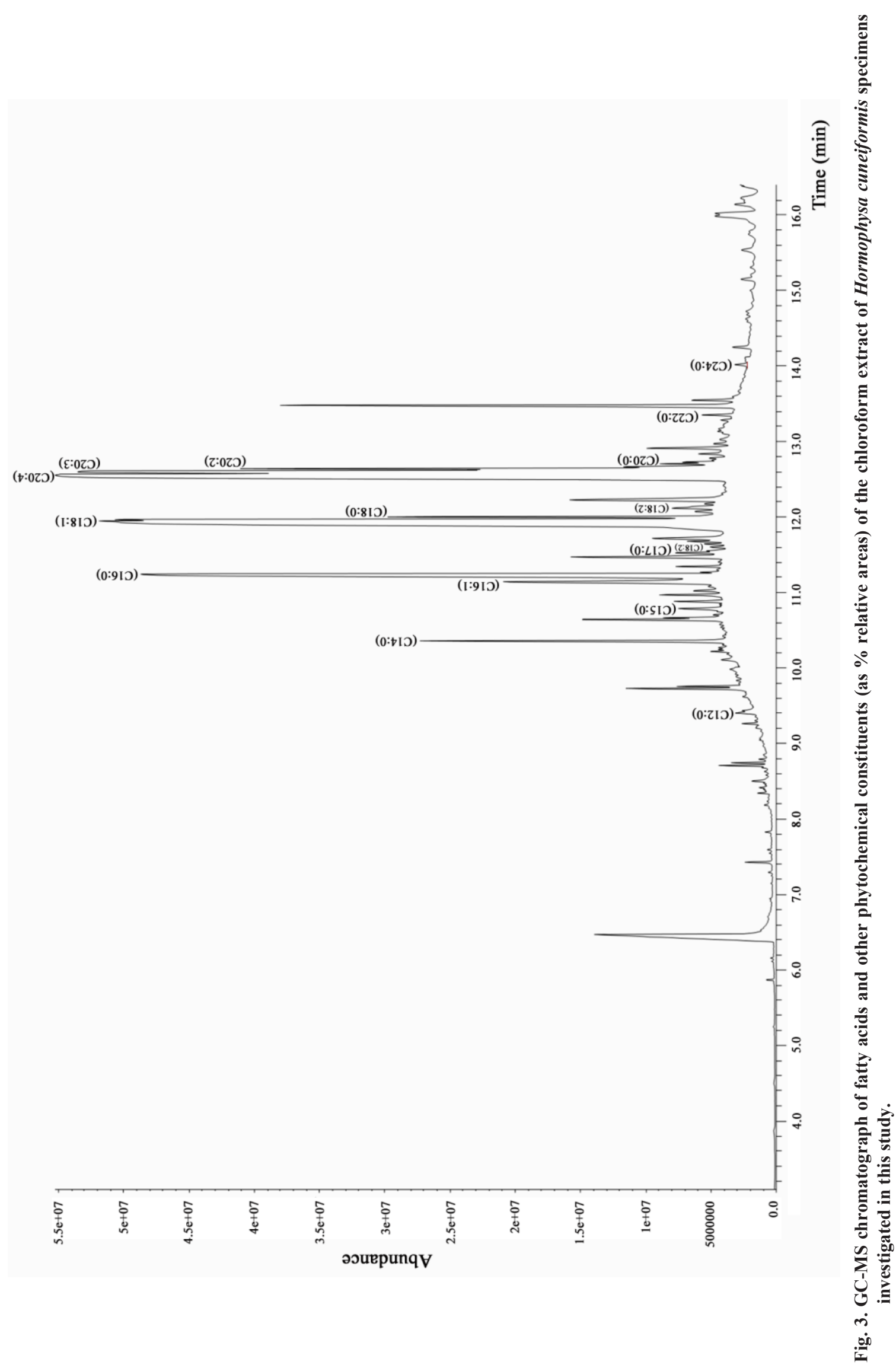

Egypt. J. Bot. 59, №. 3 (2019) 
Generally, it has been reported that mediumand long-chain unsaturated fatty acids (UFAs) have more antimicrobial activity as compared to saturated fatty acids (SFAs) with the same length of carbon chain (Desbois et al., 2008). Moreover, there is a significant link between the number of double bonds in UFA carbon chains and FA antimicrobial activity (Feldlaufer et al., 1993). On the other hand, for the SFAs, the most antimicrobial activity was reported from FAs with 10 or 12 carbons in the chain such as lauric acid (C12:0) (Wille \& Kydonieus, 2003). Accordingly, Altieri et al. (2009) found that lauric acid exerted a strong bioactivity against moulds of $F$. oxysporum (DSMZ 2018) and F. avenaceum (DSMZ 62151).

With respect to the mechanism of action, the most important target of antifungal fatty acids is the fungal cell membrane. It is probably that fatty acids caused an increase in membrane fluidity and conformational changes in membrane proteins, resulting in leakage of the fungal intracellular components and finally cell death. This is in agreement with previous studies by Avis \& Bélanger (2001), Desbois \& Smith (2010) and Pohl et al. (2011) who discussed in detail the general mechanism of antifungal fatty acids where they supposed that they naturally insert themselves into the lipid bilayer of the fungal membranes, disrupt the membranes and the electron transport chains, leading to an increased fluidity of the membranes. These variable elevations in membrane fluidity will cause a generalized disorganization of the cell membrane, resulting in conformational changes in membrane proteins, release of intracellular components, cytoplasmic disorder and eventually cell disintegration. Thibane et al. (2010) also confirmed that the antifungal activity of PUFAs may be due to their increased motional freedom inside the fungal cell membranes, leading to an increased oxidative stress that had been documented by formation of rough cell walls. In addition, Thibane et al. (2012) found that when biofilms of C. albicans and C. dubliniensis were exposed to certain PUFAs (linoleic acid, stearidonic acid, eicosapentaenoic acid and docosapentaenoic acid), there was an increase in unsaturation index of the cellular membranes and accumulation of intracellular reactive oxygen species (ROS), resulting in a programmed cellular apoptosis. This evidence was supported by reduced mitochondrial membrane potential and nuclear condensation and fragmentation. They also indicated that the most effective PUFA was stearidonic acid.
As for the possible contribution of essential oil to the antifungal activity, Vahdani et al. (2011) in their study on essential oils from five Iranian endemic medicinal plants reported that essential oils, such as tetradecene, tetradecane and hexadecane, have good antimicrobial activity against many microorganisms. Also, Kiruthiga et al. (2011) suggested that the essential oil 'cyclohexene, 4-(4-ethylcyclohexyl)-1-pentyl-', extracted from leaves of the plant Syzygium benthamianum, has a remarkable antifungal effect against Alternaria alternata, Penicillium chrysogenum and Aspergillus niger. All these antifungal compounds have been detected in this study. Recent contribution by Moghaddam et al. (2018) also supported well these observations.

\section{Conclusions}

The brown seaweed Hormophysa cuneiformis is highly recommended as an ecofriendly and promising source for bioactive compounds, mainly fatty acids, that can be useful in the treatment and/ or prevention of many human pathogenic fungal diseases and in the management and control of the plant-infecting fungal pathogens, consequently supporting the agricultural sustainable development in Egypt. However, more in-depth phytochemical studies on this interesting and rarely investigated seaweed are still required to expand our little understanding and knowledge on the structure of other powerful pharmaceutical compounds and their mode of action.

\section{References}

Abd Elmegeed, A.S., Ouf, S.A., Moussaa, T.A., Eltahlawid, S.M.R. (2015) Dermatophytes and other associated fungi in patients attending to some hospitals in Egypt. Brazilian Journal of Microbiology, 46(3), 799-805.

Abdel-Raouf, N., Ibraheem, I.B.M., Abdel-Hameed, M.S., El-Yamany, K.N. (2008) Evaluation of antibacterial, antifungal and antiviral activities of ten marine macroalgae from Red Sea, Egypt. Egyptian Journal of Biotechnology, 29, 157-172.

Abdel-Raouf, N., Al-Enazi, N.M., Ibraheem, I.B.M., Al-Harbie, R.M. (2015) Antibacterial and antihyperlipidemic activities of the brown alga Hormophysa cuneiformis from Ad Dammam Seashore. Journal of Applied Pharmaceutical Science, 5(8), 114-125. 
Altieri, C., Bevilacqua, A., Cardillo, D., Sinigaglia, M. (2009) Antifungal activity of fatty acids and their monoglycerides against Fusarium spp. in a laboratory medium. International Journal of Food Science and Technology, 44(2), 242-245.

Avis, T.J., Bélanger, R.R. (2001) Specificity and mode of action of the antifungal fatty acid cis9-heptadecenoic acid produced by Pseudozyma flocculosa. Applied and Environmental Microbiology, 67(2), 956-960.

Brown, G.D., Denning, D.W., Gow, N.A., Levitz, S.M., Netea, M.G., White, T.C. (2012) Hidden killers: Human fungal infections. Science Translational Medicine, 4, 1-6.

CLSI (Clinical and Laboratory Standards Institute) (2002) Reference method for broth dilution, antifungal susceptibility testing of filamentous fungi; Approved standard, $2^{\text {nd }}$ ed. Clinical and Laboratory Standard Institute, Wayne, PA, M38-A2.Vol. 22 No. 16.

da Silva Barros, M.E., de Assis Santos, D., Hamdan, J.S. (2007) Evaluation of susceptibility of Trichophyton mentagrophytes and Trichophyton rubrum clinical isolates to antifungal drugs using a modified CLSI microdilution method (M38-A).Journal of Medical Microbiology, 56(4), 514-518.

Dagenais, T.R., Keller, N.P. (2009) Pathogenesis of Aspergillus fumigatus in invasive aspergillosis. Clinical Microbiology Reviews, 22(3), 447-465.

Dean, R., Van Kan, J.A., Pretorius, Z.A., HammondKosack, K.E., Di Pietro, A., Spanu, P.D., Rudd, J.J., Dickman, M., Kahmann, R., Ellis, J., Foster, G.D. (2012) The top 10 fungal pathogens in molecular plant pathology. Molecular Plant Pathology, 13(4), 414-430.

Desbois, A.P., Smith, V.J. (2010) Antibacterial free fatty acids: Activities, mechanisms of action and biotechnological potential. Applied Microbiology and Biotechnology, 85(6), 1629-1642.

Desbois, A.P., Lebl, T., Yan, L., Smith, V.J. (2008) Isolation and structural characterisation of two antibacterial free fatty acids from the marine diatom, Phaeodactylum tricornutum. Applied Microbiology and Biotechnology, 81(4), 755-764.

Dixon, R.R.M., Huisman, J.M. (2015) Fucales. In:
"Algae of Australia: Marine Benthic Algae of North-western Australia. 1. Green and brown Algae", J.M. Huisman (Ed.), pp. 245-275. ABRS \& CSIRO Publishing, Canberra \& Melbourne.

El Shoubaky, G.A., Salem, E.A. (2014 a) Active ingredients fatty acids as antibacterial agent from the brown algae Padina pavonica and Hormophysa triquetra. Journal of Coastal Life Medicine, 2(7), 535-542.

El Shoubaky, G.A., Salem, E.A. (2014 b) Terpenes and sterols composition of marine brown algae Padina pavonica (Dictyotales) and Hormophysa triquetra (Fucales). International Journal of Pharmacognosy and Phytochemical Research, 6(4), 894-900.

Ells, R., Kock, J.L.F., Van Wyk, P.W.J., Botes, P.J., Pohl, C.H. (2009) Arachidonic acid increases antifungal susceptibility of Candida albicans and Candida dubliniensis. Journal of Antimicrobial Chemotherapy, 63(1), 124-128.

El-Hossary, E.M., Cheng, C., Hamed, M.M., Hamed, A.N.E., Ohlsen, K., Hentschel, U., Abdelmohsen, U.R. (2017) Antifungal potential of marine natural products. European Journal of Medicinal Chemistry, 126, 631-651.

El-Sharouny, H.M., El-Tayeb, M.A., Ismail, M.S. (2001) Macroalgae associated with mangroves at Hurghada and Safaga of the Egyptian Red Sea coast. Journal of King Abdulaziz University: Marine Sciences, 12(1), 241-251.

El-Sheekh, M.M., Gharieb, M.M., El-Sabbagh, S.M., Hamza, W.T. (2014) Antimicrobial efficacy of some marine macroalgae of Red Sea. International Journal of Microbiology and Immunology Research, 3(3), 21-28.

Fathy, S.A., Mohamed, S.S., Ghareeb, D.A., Emam, M.A., Abd-El Megeed, D.F. (2017) In vitro screening of anticandidal activity of some marine algae extracts collected from Abo- Qir bay (Alexandria, Egypt). Egyptian Journal of Experimental Biology (Botany), 13(2), 225-231.

Feldlaufer, M.D., Knox, D.A., Lusby, W.R., Shimanuki, H. (1993) Antimicrobial activity of fatty acids against Bacillus larvae, the causative agent of American foulbrood disease. Apidologie, 24(2), 95-99. 
Fisher, M.C., Henk, D.A., Briggs, C.J., Brownstein, J.S., Madoff, L.C., McCraw, S.L., Gurr, S.J. (2012) Emerging fungal threats to animal, plant and ecosystem health. Nature, 484(7393), 186-194.

Folch, J., Lees, M., Sloane Stanley, G.H. (1957) A simple method for the isolation and purification of total lipids from animal tissues. Journal of Biological Chemistry, 226(1), 497-509.

Garcia-Solache, M.A., Casadevall, A. (2010) Global warming will bring new fungal diseases for mammals. MBio, 18(1). pii: e00061-10.

Guedes, E.A., Araújo, M.A., Souza, A.K., de Souza, L.I., de Barros, L.D., Maranhão, F.C., Sant'Ana, A.E. (2012) Antifungal activities of different extracts of marine macroalgae against dermatophytes and Candida species. Mycopathologia, 174(3), 223232.

Hamed, S.M., Abd El-Rhman, A.A., Abdel-Raouf, N., Ibraheem, I.B.M. (2018) Role of marine macroalgae in plant protection and improvement for sustainable agriculture technology. Beni-Suef University Journal of Basic and Applied Sciences, 7(1), 104110.

Hammer, K.A., Carson, C.F., Riley, T.V. (2003) Antifungal activity of the components of Melaleuca alternifolia (tea tree) oil. Journal of Applied Microbiology, 95(4), 853-860.

Heiba, H.I., Al-Easa, H.S., Rizk, A.M. (1997) Fatty acid composition of twelve algae from the coastal zones of Qatar. Plant Foods for Human Nutrition, 51(1), 27-34.

Ibraheem, I.B.M., Abdel-Raouf, N., Abdel-Hameed, M.S., El-yamany, K. (2012) Antimicrobial and antiviral activities against Newcastle disease virus (NDV) from marine algae isolated from Qusier and Marsa-Alam Seashore (Red Sea), Egypt. African Journal of Biotechnology, 11(33), 8332-8340.

Ibraheem, I.B.M., Abdel-Raouf, N., Mohamed, H.M., Yehia, R., Hamed, S.M. (2017) Impact of the microbial suppression by using the brown alga Dictyotadichotoma extract. In: The $7^{\text {th }}$ International Conference", Plant \& Microbial Biotechnology $\&$ their Role in the Development of the Society. Egyptian Journal of Botany (Speical Issue), 205214.
Jha, B., Reddy, C.R.K., Thakur, M.C., Rao, M.U. (2009) "Seaweeds of India: The Diversity and Distribution of Seaweeds of the Gujarat Coast". Springer Science+Business Media B.V., Dordrecht, $215 p$.

Kiruthiga, K., Saranya, J., Eganathan, P., Sujanapal, P., Parida, A. (2011) Chemical composition, antimicrobial, antioxidant and anticancer activity of leaves of Syzygium benthamianum (Wight ex Duthie) Gamble. Journal of Biologically Active Products from Nature, 1(4), 273-278.

Kullberg, B.J., Arendrup, M.C. (2015) Invasive candidiasis. New England Journal of Medicine, 373(15), 1445-1456.

Liu, A.H., Liu, D.Q., Liang, T.J., Yu, X.Q., Feng, M.T., Yao, L.G., Fang, Y., Wang, B., Feng, L.H., Zhang, M.X., Mao, S.C. (2013) Caulerprenylols A and B, two rare antifungal prenylatedpara-xylenes from the green alga Caulerpa racemosa. Bioorganic and Medicinal Chemistry Letters, 23(9), 2491-2494.

Magaldi, S., Mata-Essayag, S., Hartung de Capriles, C., Perez, C., Colella, M.T., Olaizola, C., Ontiveros, Y. (2004) Well diffusion for antifungal susceptibility testing. International Journal of Infectious Diseases, 8(1), 39-45.

Martinelli, F., Scalenghe, R., Davino, S., Panno, S., Scuderi, G., Ruisi, P., Villa, P., Stroppiana, D., Boschetti, M., Goulart, L.R., Davis, C.E., Dandekar, A.M. (2015) Advanced methods of plant disease detection. A review. Agronomy for Sustainable Development, 35(1), 1-25.

Mason, M.E., Waller, G.R. (1964) Dimethoxypropane induced transesterification of fats and oils in preparation of methyl esters for gas chromatographic analysis. Analytical Chemistry, 36(3), 583-586.

Mhadhebi, L., Chaieb, K., Bouraoui,A. (2012) Evaluation of antimicrobial activity of organic fractions of six marine algae from Tunisian Mediterranean coasts. International Journal of Pharmacy and Pharmaceutical Sciences, 4(1), 534-537.

Moghaddam, M., Mehdizadeh, L., Najafgholi, H.M., Pirbalouti, A.G. (2018) Chemical composition, antibacterial and antifungal activities of seed essential oil of Ferulago angulata. International Journal of Food Properties, 21(1), 158-170. 
NCCLS (National Committee for Clinical Laboratory Standards) (2002 a) Reference method for broth dilution antifungal susceptibility testing of yeasts; Approved standard. NCCLS document M27-A2. NCCLS, Wayne, PA, USA. Vol. 17, No. 9.

NCCLS (National Committee for Clinical Laboratory Standards) (2002 b) Reference method for broth dilution antifungal susceptibility testing of conidium-forming filamentous fungi: Proposed standard. NCCLS document M38-A. NCCLS, Wayne, PA, USA.

Ouf, S.A., Moussaa, T.A., Abd Elmegeed, A.S., Eltahlawi, S.M.R. (2016) Anti-fungal potential of ozone against some dermatophytes. Brazilian Journal of Microbiology, 47(3), 697-702.

Pohl, C.H., Kock, J.L.F., Thibane, V.S. (2011) Antifungal free fatty acids: A review. In: "Science against Microbial Pathogens: Communicating Current Research and Technological Advances", A. Méndez-Vilas (Ed.), pp. 61-71. Formatex Research Center, Badajoz.

Righini, H., Roberti, R., Baraldi, E. (2018) Use of algae in strawberry management. Journal of Applied Phycology, 30(6), 3551-3564.

Shabaka, S.H. (2018) Checklist of seaweeds and seagrasses of Egypt (Mediterranean Sea): A review. Egyptian Journal of Aquatic Research, 44(3), 203212.

Shobier, A.H., Abdel Ghani, S.A., Barakat, K.M. (2016) GC/MS spectroscopic approach and antifungal potential of bioactive extracts produced by marine macroalgae. Egyptian Journal of Aquatic Research, 42(3), 289-299.
Soliman, A.S., Ahmed, A.Y., Abdel-Ghafour, S.E., ElSheekh, M.M., Sobhy, H.M. (2018) Antifungal bioefficacy of the red algae Gracilaria confervoides extracts against three pathogenic fungi of cucumber plant. Middle East Journal of Applied Sciences, 8(3), 727-735.

Thibane, V.S., Kock, J.L.F., Ells, R., van Wyk, P.W.J., Pohl, C.H. (2010) Effect of marine polyunsaturated fatty acids on biofilm formation of Candida albicans and Candida dubliniensis. Marine Drugs, 8(10), 2597-2604.

Thibane, V.S., Ells, R., Hugo, A., Albertyn, J., van Rensburg, W.J., van Wyk, P.W., Kock, J.L., Pohl, C.H. (2012) Polyunsaturated fatty acids cause apoptosis in $C$. albicans and $C$. dubliniensis biofilms. Biochimicaet Biophysica Acta, 1820(10), 1463-1468.

Vahdani, M., Faridi, P., Zarshenas, M.M., Javadpour, S., Abolhassanzadeh, Z., Moradi, N., Bakzadeh, Z., Karmostaji, A., Mohagheghzadeh, A., Ghasemi, Y. (2011) Major compounds and antimicrobial activity of essential oils from five Iranian endemic medicinal plants. Pharmacognosy Journal, 3(22), 48-53.

Vincent, J.L., Rello, J., Marshall, J., Silva, E., Anzueto, A., Martin, C.D., Moreno, R., Lipman, J., Gomersall, C., Sakr, Y., Reinhart, K. (2009) International study of the prevalence and outcomes of infection in intensive care units. JAMA, 302(21), 2323-2329.

Wille, J.J., Kydonieus (2003) Palmitoleic acid isomer (C16:1 $\Delta 6)$ in human skin sebum is effective against Gram-positive bacteria. Skin Pharmacology and Physiology, 16(3), 176-187. 


\title{
القدرة المضادة للفطريات للمواد الفعالة المستخلصة من الطحلب البحرى البنى هورموفيسا

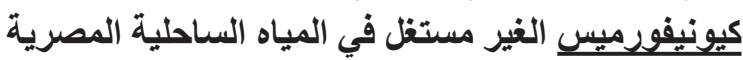

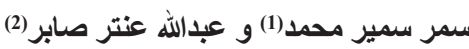

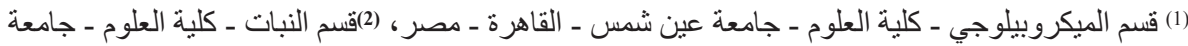

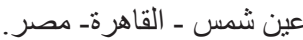

\begin{abstract}
تعتبر الإصابات الفطرية الممرضة للإنسان و النبات من العو امل المؤثرة على الصحة العامة و إنتاج المحاصيل.

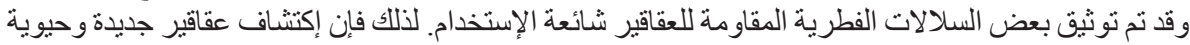

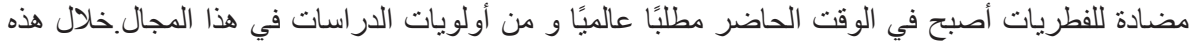

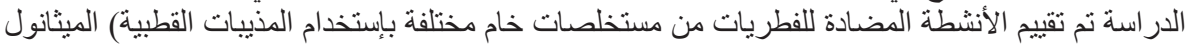

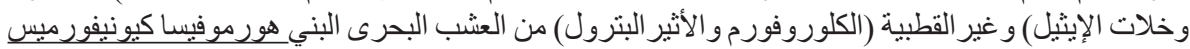

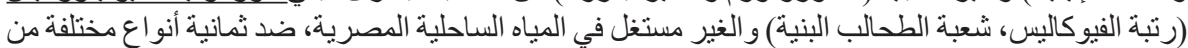

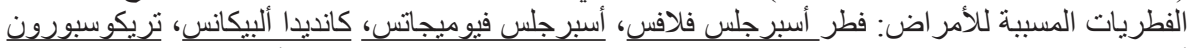

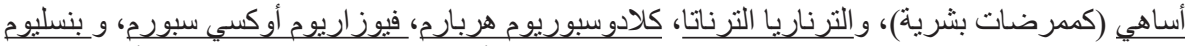

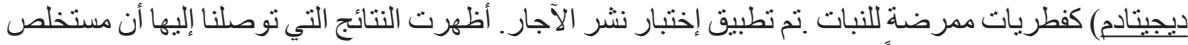

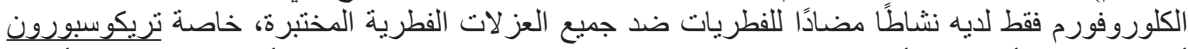

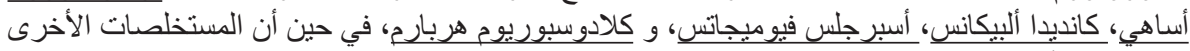

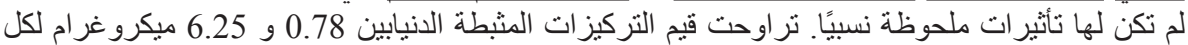

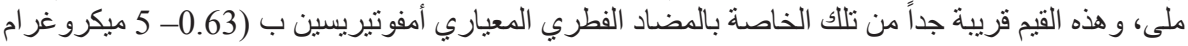

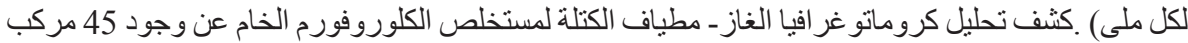

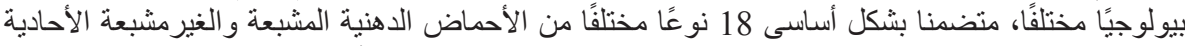

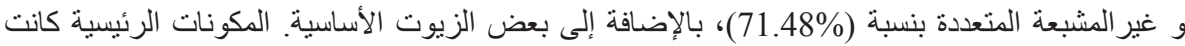

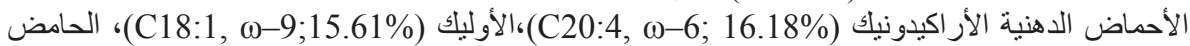

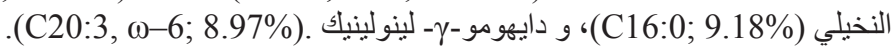

